\title{
O ESPETÁCULO EXPERIMENTADO: O PLANO-SEQUÊNCIA E 0 CINEMA REALISTA
}

Yves Marcel de Oliveira São Paulo ${ }^{1}$

RESUMO: Partindo da teoria da atenção de Hugo Munsterberg e sobre o pensamento do plano-sequência de André Bazin, fazemos no presente estudo o questionamento sobre a forma de um cinema realista. Realista não simplesmente no sentido de apresentar detalhes da realidade, mas de ser capaz de inserir o espectador na obra. $\mathrm{O}$ espectador participando do espetáculo faria mais que assisti-lo, o experimentaria. Para isso é necessário um estudo das formas do cinema, levando em conta suas técnicas. No presente artigo será feito este exercício de pensamento do cinema, introduzindo-nos brevemente em sua história até o momento em que o plano-sequência passa a desempenhar papel importante dentro da cinematografia mundial.

PALAVRAS-CHAVE: Estética; Cinema; Duração; Espectador; Realismo.

ABSTRACT: Starting with the theory about attention by Hugo Munsterberg and the theory of the long take by André Bazin, we make on the present study a question concerning the form of the realistic cinema. This realism is not just in the meaning of showing details of the reality, but also of being capable of 
insert the spectator on the movie. The spectator participation of the spectacle would do more than just watch it, he would experience it. For this it's necessary a study of the cinema forms, remembering its techniques. On the present article will be done this exercise of thinking the cinema, introducing us briefly into its history till the moment the long take comes to play an important part on the world cinematography.

KEYWORDS: Aesthetics; Cinema; Duration; Spectator; Realism. 


\section{INTRODUÇÃO}

No presente artigo será tratada a relação entre espectador e obra cinematográfica. A obra artística é feita vislumbrando o impacto estético que terá em seu receptor - no caso do cinema o espectador. Este impacto estético é formatado por um pensamento do autor (no presente caso, do cineasta) que quer passar uma sensação, sentimento e/ou ideia a quem se depara com sua obra. Para que tal seja feito é necessário que ele, o artista, conheça muito bem as características da arte que escolheu para se expressar.

A relação do espectador com o cinema sempre foi um dos principais pontos guiadores da concepção de um filme. Na época do cinemamudoaspelículaseramfeitasdetalmodoquequemassistisse a obra pudesse compreender a história sem a necessidade do uso da palavra falada (não presente neste cinema) e da palavra escrita (que era utilizada quando o autor se deparava com um problema que não conseguia traduzir por meio de imagens, se valendo de letreiros que interrompiam a ação). Com o passar do tempo esta relação distante do filme com o espectador já não é suficiente.

Surge, assim, a ideia de um "cinema moderno". Nele é necessário que o espectador se faça presente e atento para que possa compreender o filme que se põe a assistir. Porque as informações já não serão postas no filme objetivamente. Será necessário seu trabalho intelectual para que possa captar tais informações presentes nas películas cinematográficas. Neste estudo será levantada esta questão tendo como guias o psicólogo Hugo Munsterberg e o crítico de cinema André Bazin. Procurarse-á a justificação para a afirmação: o cinema moderno não é simplesmente assistido, mas vivenciado pelo espectador. 


\section{HUGO MUNSTERBERG E A ATENÇÃO}

Ainda nos processo de formação de uma linguagem cinematográfica, Hugo Munsterberg dedica toda uma obra ao estudo do cinema: The Photoplay. Seu conhecimento de cinema se refere a um conjunto de filmes primitivos, em que as experimentações artísticas começavam a ganhar contornos. Esta nova arte buscava encontrar uma forma própria de apresentar uma narrativa - fictícia ou documental - partindo de suas particularidades. Uma destas particularidades que logo saltavam aos olhos tanto de cineastas quanto de espectadores era a montagem. Por meio dela torna-se possível contar uma história em diferentes locais sem necessidade de interrupção da narrativa - assim como em diferentes momentos do tempo.

O espectador, ao assistir um filme, o faz com a mente cheia de ideias. Isto porque o espetáculo que se desenrola perante seus olhos necessita de sua atenção para que seja capaz de chegar a um entendimento do desenrolar da trama e do conjunto de ideias que são postas por detrás das imagens. Mais do que suscitar ideias, a atenção que dedicamos ao filme leva o espectador à mobilização de sentimentos e emoções. "Uma infinidade desses processos interiores deve ir de encontro ao mundo das impressões" (MUNSTERBERG, 1983, p. 27).

Esta é vista por Munsterberg como sendo a mais importante das funções internas de organização do caos de informações que se apresenta no mundo exterior: a atenção. É ela que fornece ao sujeito ferramentas para que possa organizar e significar as partes constituintes do mundo externo de acordo com sua percepção. "Tudo o que entra no foco da atenção se destaca e irradia significado no desenrolar dos acontecimentos" (MUNSTERBERG, 1983, p. 
28). Daí a distinção de dois tipos de atenção, ambas que servem ao entendimento da relação do espectador com o espetáculo cinematográfico: a atenção voluntária e a atenção involuntária.

A atenção involuntária se dá quando "o foco da atenção é dado pelas coisas que percebemos" (MUNSTERBERG, 1983, p. 28). Se forem apresentados num palco teatral, ou mesmo numa cena filmada em plano geral (que possibilite a visão de todo cenário), dois atores conversando, a atenção do espectador é direcionada àquele que fala. No cinema esta função de direcionamento é feita pelo próprio filme. Se um personagem toma a fala há um corte e somente ele é visto na tela. Todo o resto do cenário é excluído para que um detalhe mais importante seja notado: neste caso, o homem que fala. $\mathrm{O}$ mesmo poderia se dar quando, dois personagens conversando, um deles pegasse um revolver. Ainda que escute a conversa, a atenção de quem assiste se direciona para aquele ato em particular.

O cinema possui este poder de fracionar o espaço e ter a atenção de quem assiste dirigida pelo filme. É esquecido por algum momento o restante do espaço para que somente uma parte dele seja notada. O filme torna-se uma experiência quase sensorial, uma vez que são escolhidos aqueles detalhes que provocariam uma reação emocional em quem o assiste ou mesmo, como seria proposta pela escola de montagem soviética, a produção de uma ideia pelo choque de duas imagens distintas.

Este modelo de cinema que tem na montagem seu solo base de construção e que estava em desenvolvimento quando Munsterberg escreve seu livro, é visto pelo psicólogo alemão como sendo mais realista do que os filmes feitos nos primórdios do cinema quando as cenas eram filmadas à distância, apresentando um cenário pouco realista e diversas ações que transcorriam ao mesmo tempo. Seria 
mais realista este outro processo em que o cenário é fracionado de tempos em tempos para que um detalhe surja em tela. "Começa aqui o cinema", escreve Munsterberg, "a mão nervosa que agarra febrilmente a arma mortífera pode súbita e momentaneamente crescer e ocupar toda tela" (MUNSTERBERG, 1983, p. 34). A atenção que se dá dentro da mente acontece no mundo externo, remodelando o espaço. Como muitos escritores que se dedicaram a escrever sobre o cinema em suas primeiras décadas de existência, também Munsterberg tece elogios ao close-up: "o close-up transpôs para o mundo da percepção o ato mental da atenção" (MUNSTERBERG, 1983, p. 34) dando ao cinema um meio extremamente poderoso de criação dramática.

De outro lado há a atenção voluntária. Esta se apresenta quando, "cientes de antemão do objetivo que queremos atingir, subordinamos tudo o que encontramos à sua energia seletiva" (MUNTERBERG, 1983, p. 28). No teatro o espectador é confrontado com toda uma diversidade de informações presentes no palco. Por meio do trabalho de seleção daquilo que seria mais importante para sua compreensão e imersão na peça, o espectador direciona sua atenção para um determinado ponto do cenário. Se no cinema é possível o recorte do espaço para que somente parte dele - considerada mais importante naquele momento - seja vista, no teatro este trabalho é promovido pela mente do espectador. Se um ator no palco pega um revolver, o espectador selecionará esta ação e deixará de lado todo o resto.

Nos primórdios do cinema, os filmes eram filmados de modo a se assemelharem ao teatro. Encontrava-se impressa na imagem cinematográfica toda a extensão do palco em que os atores se apresentavam e onde encenavam as histórias. A câmera era posta à distância ganhando a característica de 
um observador que não participa da ação, assemelhando-se à quarta parede faltante do cenário. Este posicionamento da câmera passaria a ser chamado de "regente de orquestra". Como exemplo encontra-se os primeiros filmes de Charles Chaplin.

Em Carlitos no hotel (NORMAND, 1914) a câmera fixa é posta a distância possibilitando o visionamento de diferentes personagens e ações num mesmo quadro e a diferentes distâncias da máquina de filmar. Carlitos, o vagabundo interpretado por Chaplin, aparece em cena bêbado e sentado em uma poltrona no lobby do hotel. Neste mesmo quadro é possível ver ainda duas mulheres que conversam no canto direito da imagem. Em seguida, surgindo de uma cena anterior, entra em quadro Mabel com um cachorro. Os diferentes personagens que aparecem na cena fazem suas ações em simultaneidade, sem que um dê espaço para que o outro chame maior atenção: A) Carlitos tem um olhar depravado para as mulheres; B) as mulheres conversam; e C) Mabel demonstra por meio de seus gestos que está apaixonada. A atenção do espectador nesta cena pode ser devotada a qualquer um dos personagens que surgem em equidade no quadro, cabe a quem assiste escolher para onde olhar.

Seria ainda nestes primeiros anos do cinema - que compreende aos vinte primeiros anos, entre 1895 a 1915 que grande parte dos filmes se assemelharia a um "teatro filmado". Munsterberg, provavelmente ecoando as vozes de milhares de outros espectadores, escreve em seu livro que esta forma de filmar não é compatível com o cinema, sendo muito mais bonito e alcançando melhores resultados dramáticos no teatro. Seria próprio ao cinema o corte e, consequentemente, o close-up. Seria por meio deles que o cinema encontraria o seu realismo. Não um realismo político como seria defendido 
décadas mais tarde, mas um realismo dramático em que o espectador pudesse acreditar e se entregar à obra que assiste.

Mas isto não significa que este modo de filmar, de planos de longa duração, sem corte, que apresentam mais de uma figura no quadro, não seria cinematográfico. Foi necessário que se desse tempo até que encontrasse nele uma forma de filmar que o fizesse parecer realista. Dentro da teoria de Munsterberg é encontrado um detalhe que poderia servir de motivação pelo qual se tentaria revitalizar tal forma: o espectador de cinema que se habituou a ser dirigido, a receber todas as respostas, passaria a ser desafiado, a participar do filme, a encontrar sem a ajuda do cineasta por trás da obra os significados que a movem.

\section{O CINEMA MODERNO E O PLANO-SEQUÊNCIA}

Durante a década de 1930 as cinematografias de todo o mundo tentavam se adaptar ao cinema falado. Surgido ainda no fim dos anos 1920 nos EUA, o advento da fala no cinema fez mais do que pôr os personagens a conversarem em cena: ele provocou uma revolução na forma como eram encenados os filmes. Em Hollywood, durante os primeiros "experimentos" sonoros, os filmes eram gravados com várias câmeras para que se tivesse uma continuidade do som - o que prejudicava a composição do quadro (COUSINS, 2011). Com o passar do tempo descobriu-se que não era necessário tanto trabalho e que a composição de quadro ainda podia ser feita com o devido cuidado.

A revolução da encenação parte do princípio de que os atores agora podiam usar a palavra falada para expressar o que sentem seus personagens. Antes seria necessário que o intérprete se valesse 
de caretas e trejeitos exagerados para expressar aquilo que exigia a história. Chaplin relata em sua autobiografia o trabalho que teve quando, ainda em 1931, tentou escalar atores para a produção deum filme mudo: apesar de há menos de cinco anos estivesse instalado o sistema sonoro, os atores não mais conseguiam representar para um filme sem falas. "Toda a sua noção de ritmo na representação transferira-se do gesto para a fala" (CHAPLIN, 2012, p. 379).

$\mathrm{O}$ trabalho dos roteiristas ganha maior importância. O que passa a ser o principal do filme já não é mais sua construção imagética, mas as relações dos atores e o texto que pronunciam. O cinema fica a beira de se transformar em teatro. Por outro lado há um enorme ganho para a representação realista. Se os atores podem falar, os filmes passam a cada vez mais se assemelhar com a vida cotidiana. Os roteiristas escrevem diálogos mais realistas que os atores recitam com rapidez, superpondo uma fala sobre a outra como numa conversa banal.

Neste ponto destacam-se alguns cineastas que utilizam este novo cinema para fazer uma forma própria de cinema e assim encontrar a adequação da arte cinematográfica ao seu novo modo de representação. Para citar alguns: Orson Welles, Jean Renoir e John Ford. Estes três cineastas utilizaram o cinema falado para poder filmar tomadas mais longas, mas não cansativas guiadas principalmente pela fala dos atores. Jean Renoir é o primeiro deste grupo a fazer um filme que siga estes moldes. A regra do jogo (RENOIR, 1936) é filmado em profundidade de campo em plano-sequência. Isto significa que em diversas cenas Renoir filma diversos personagens que estão presentes em um mesmo quadro sem precisar de corte para pô-los ou apresentá-los em cena. Todos eles desempenham suas funções próprias, falam ao mesmo tempo, interagem uns com os outros. Toda esta 
multiplicidade é captada pela câmera fazendo deste filme um marco na cinematografia mundial. Assemelha-se ao primeiro filme dos irmãos Lumière em que os operários deixam a fábrica em que trabalham, mas diferente deste, Renoir faz com que exista uma dinâmica da relação entre os personagens com a câmera e com o cenário em que se desenrola a ação. A câmera não observa, apenas, ela participa daquele jogo. Surge então um termo que será muito caro à discussão de cinema: mise-en-scène.

A mise-en-scène pode ser traduzida como encenação, sendo um termo proveniente do teatro. Frequentemente é utilizada em francês, mesmo no Brasil, para que seja pautada a diferença entre a mise-en-scène do cinema e a encenação do teatro. As duas artes se valem da expressão de um ator que faz a performance dramática de um texto. Mas diferente do teatro, o cinema possui um adendo: a técnica. Esta seria uma referência aos processos de filmagem (em que a câmera faz parte do processo de criação dramática juntamente com o ator, sendo tão importante quanto este) e de montagem. No caso da encenação fílmica (a miseen-scène), "a câmera e sua mobilidade ampliam os recursos expressivos, potencializando a dramaticidade dos fatos e dos gestos" (OLIVEIRA JR, 2010, p. 10), a partir do momento em que são selecionados no quadro determinados detalhes que por si só servem de expressão de determinada ideia, sensação ou emoção.

Estes detalhes que são selecionados pela câmera e organizados pela montagem podem se assemelhar à atenção involuntária que mencionava Munsterberg. Mas não somente por meio de cortes é possível que tal trabalho seja feito. Exemplo disso é Festim diabólico (HITCHCOCK, 1948) de Alfred Hitchcock, filme de uma hora e meia, constituído de um único longo plano. A câmera passeia pelo cenário e, não raro, seleciona certos detalhes 
fazendo com que o resto do espaço despareça da tela por alguns instantes. Este longo plano passou a ser conhecido como planosequência antes mesmo deste "experimento" de Hitchcock. Ele já estava presente, por exemplo, no já citado $A$ regra do jogo.

$O$ plano-sequência possui como principal característica a de apresentar a ação em sua completude, o que significa a anulação do corte na cena. Se certo detalhe é prezado pelo diretor a aparecer em cena e tomar todo o quadro, a câmera se moverá até ele. Mas a escolha que se faz do plano-sequência normalmente visa à apresentação da ação como um todo, filmar a realidade em seu fluxo contínuo sem fazer a seleção de determinado detalhe que vá excluir o resto do espaço.

Poucos anos depois do famoso filme de Renoir, Orson Welles lança sua grande obra: Cidadão Kane (WELLES, 1941). Nela Welles, que chegava ao cinema depois de ter feito muito sucesso no teatro e na rádio, leva ao mundo da sétima arte um modelo de encenação semelhante àquele que havia aprendido em seus anos como diretor teatral. Unido a este conhecimento está o saber de quem assistiu e absorveu aquilo que lhe seria muito caro na miseen-scène. Os atores são espalhados pelo cenário com muito cuidado. Provavelmente influenciado pelo cinema nazista e sua forma de filmar Hitler - sempre filmado de baixo para cima, para enaltecêlo, fazê-lo grande - Cidadão Kane segue semelhante caminho. As distâncias entre os personagens em cena são exploradas para que a figura do magnata das comunicações, Charles Foster Kane, sempre apareça em tela maior e mais imponente do que seus súditos. Apesar de distantes da tela, todos os atores aparecem no quadro em foco, não importa qual seja a distância que os separe de Kane, este constantemente filmado em primeiro plano também em foco. 
Este é um detalhe técnico de muita relevância para a compreensão do plano-sequência. Certas lentes não permitem que um ator ou objeto posicionado próximo à câmera apareça em quadro em foco se este [o foco] for dado a um ator ou objeto ao fundo do cenário. $\mathrm{O}$ trabalho com um novo conjunto de lentes permitiu ao cinema esta "evolução" da mise-en-scène. Não é mais necessário o corte para mostrar a influência ou perigo de um objeto ou personagem sobre o outro. Ambos podem ser filmados juntos em um quadro mesmo que não estejam em um mesmo ambiente. É possível filmar um assassino que, do lado de fora da casa, olha pela janela sua vítima, sendo que ambos aparecem em quadro e em foco. Descobre-se, assim, algo de novo: o realismo cinematográfico.

O realismo permitido pelo plano-sequência permite que determinada ação seja filmada sem que o corte promova a sensação de ilusão. Quando Martin Scorsese filma o gangster Henry Hill em Os bons companheiros (SCORSESE, 1990) em um único plano saindo de sua casa, atravessando a rua e espancando o seu vizinho que havia flertado com sua namorada, a violência da cena se dá por esta sensação que o espectador tem de não ter sido enganado. Não havia um truque de montagem que no meio da cena mostrava um close-up do rosto do homem sangrando ou para sugerir que Henry Hill estivesse realmente batendo no vizinho. Há em cena todos estes detalhes que surgem com "naturalidade".

O plano-sequência como um retrato realista do mundo, que influenciaria Scorsese décadas mais tarde, surge como base de todo um movimento cinematográfico de grande influência na história do cinema: o neorrealismo italiano. Nele, é retratado o povo italiano e as ruas onde suas vidas ocorrem. A encenação se aproxima daquela de Cidadão Kane, mas desta vez as marcações de atores não é tão precisa, é necessário que 
a naturalidade de suas ações seja registrada. Para isso, não raro, serão empregados não-atores para atuarem nos filmes. Em Roma, cidade aberta (1945), Roberto Rossellini faz o filme inaugural e ao mesmo tempo manifesto do movimento. Na obra são retratados dois lados: o povo italiano que sofre com a guerra e os militares nazistas que buscam destruir os movimentos de resistência. São duas formas distintas de filmar estes dois cenários diferentes. O povo italiano é filmado nas ruas, com luz natural, com a câmera que os segue registrando seus passos por meio de planos-sequência que concedem ao filme o caráter realista - quase documental - almejado. Os nazistas são filmados seguindo os moldes clássicos de mise-en-scène: com os cortes (como o cinema objetivo citado anteriormente, preferido por Munsterberg), luz artificial, encenação precisa.

Influenciados por tal movimento surgirão muitos outros, inclusive o cinema novo brasileiro. É o neorrealismo italiano que mostra para o público uma realidade que eles conhecem; o espectador passa a se identificar com o filme porque reconhece os personagens (eles se assemelham a pessoas com quem ele convive) e cenários que são apresentados (ele anda por aquelas ruas ou em ruas semelhantes em seu cotidiano). Para o presente estudo, o neorrealismo oferece um marco de muita importância: é o movimento que rompe a barreira entre espectador e filme quando faz com que quem assiste se identifique com a obra - não mais de modo distante com uma consonância de sentimentos entre espectador e personagem, mas como uma realidade que poderia ser a dele, do espectador. Mais do que isso, o espectador se torna crítico frente ao que é apresentado em tela: e assim nasce o chamado "cinema moderno". 


\section{ANDRÉ BAZIN E A DURAÇÃO}

Um dos principais defensores do cinema moderno e do planosequênciaéocrítico de cinemafrancês AndréBazin. Sua construção teórica se faz presente em um conjunto de artigos escritos ao longo de sua vida em diversas revistas de seu país natal. Tendo morrido ainda muito jovem (aos 40 anos), Bazin não pôde escrever uma obra em que apresente detalhadamente seu pensamento. Pouco antes de falecer, em 1958, ele organizou uma série de livros em que selecionou alguns textos publicados ao longo de sua carreira e que serviriam para o entendimento de seu pensamento. Esta série foi intitulada $O$ que é o cinema?, e nela se encontram alguns textos de grande importância para o presente estudo.

$\mathrm{Na}$ construção teórica de Bazin é clara a influência do pensamento de Henri Bergson, principalmente quando o crítico se vale de um termo próprio da filosofia bergsoniana: a duração. Esta será tomada como parte constituinte de uma argumentação de defesa do realismo e do plano-sequência, possuindo dentro da construção baziniana um entendimento próprio, não tão fiel à formulação do citado filósofo ${ }^{2}$.

O realismo do cinema estaria garantido pelo seu processo de registro fotográfico. Seria a fotografia, segundo Bazin, que teria libertado as artes plásticas de sua necessidade de semelhança com o mundo, da busca de um realismo. A fotografia daria a possibilidade de representação do objeto fotografado, ou representado. Estariam ali presente os fantasmas de um passado registrados permanentemente. A pessoa retratada em uma fotografia teria um momento de sua duração paralisadoe registrado pela objetiva. "A fotografia se beneficia de uma transferência da realidade para sua reprodução" (BAZIN, 2014, p. 32). 
No cinema há um algo a mais. Nele, as imagens já não são simplesmente um momento fixo conservado eternamente. "Pela primeira vez, a imagem das coisas é também a de sua duração" (BAZIN, 2014, p. 33). Isto porque o cinema tem a capacidade de retratar o mundo não somente em sua característica espacial, mas também temporal. Quando da captação da realidade pela objetiva dacâmera defilmar, também seria captado ofluxo de seu desenrolar. Esta ideia do fluxo contínuo é de extrema importância para que se possa compreender a presença de Bazin no presente estudo.

O cinema moderno pensado pelo crítico francês recusaria o corte que fragmenta o espaço em que se desenrolam os eventos filmados para que permitisse a expressão do fluxo contínuo dos acontecimentos. O plano-sequência seria o grande trunfo desse novo cinema para que pudesse captar a duração dos acontecimentos registrados. É daí que parte o choque de uma cena como a de Os bons companheiros citada anteriormente. A câmera que corre atrás de Henry Hill daria a semelhança de ser o espectador uma figura presente naquele ambiente e que segue o protagonista. E tal como acontece na vida real, não seria dada a possiblidade de corte daquele momento maior agressividade (a não ser que o sujeito presente naquele momento fechasse os olhos).

Estaria presente no pensamento baziniano a relação entre o espaço dramático e a captação da duração. O respeito pelo espaço dramático - que se daria no ato de evitar a sua fragmentação - seria um aliado no sucesso da representação do fluxo contínuo dos acontecimentos e a consequente expressão da duração dos fatos representados. O realismo de Bazin remaria em um sentido próprio de uma afirmação como: se "as coisas estão aí, porque manipulá-las?” (XAVIER, 1977, p. 68). 
O plano-sequência, respeitando a unidade espaçotemporal dos acontecimentos, teria em sua base realista certa respeitabilidade pelo desenrolar das ações cotidianas, partindo daí a formulação de que um filme construído por planos-sequência seria um filme ambíguo. Esta ambiguidade, diz Bazin, não seria possível no cinema analítico da decupagem clássica. Neste, o espectador somente vê o que o diretor lhe manda ver, no plano-sequência o espectador vê o que quer ver. Seria a atenção voluntária de Munsterberg, mas desta vez vista como um processo nitidamente cinematográfico possuidor de caráter realista.

Esta ambiguidade conferida ao filme pelo plano-sequência o faria diferir radicalmente daquele formado pela decupagem clássica. Esta [a decupagem clássica] é objetiva porque a montagem dá o significado de todos os elementos surgidos no filme. Bazin dá o exemplo do experimento de Lev Kulechov em que um mesmo rosto sem qualquer expressão bem definida seguido por diferentes imagens podem lhe conceder significados diferentes (BAZIN, 2014, p. 108). Se fosse escolhida outra imagem para compor as cenas ter-se-ia um filme completamente diferente. É o caso da atenção sendo dirigida pelo diretor como afirma Munsterberg. Já o plano-sequência é ambíguo porque insere o espectador dentro do filme e permite que este dê a significação às imagens (ou busque seu sentido). Mas para além do espectador que procura dar significação às imagens, reside também impressa na película a permanência do mistério que é o mundo.

\section{O ESPETÁCULO EXPERIMENTADO (CONCLUSÃO)}

Seria uma proposta do cinema moderno não mais entregar em uma bandeja, ao espectador, todas as respostas prontas do filme. $\hat{E}$ 
necessária que seja feita a libertação e emancipação do sujeito que assiste a uma obra cinematográfica para que este não mais aceite passivamente o que lhe é posto. Da parte do filme, seu objetivismo é deixado de lado. As imagens deixam de possuir uma significação objetiva como tiveram nos filmes feitos outrora. Eisenstein via na montagem cinematográfica um meio objetivo de fazer um cinema ideológico: a sucessão de imagens diferentes levaria o espectador a uma ideia específica concebida pelo autor. No neorrealismo a montagem não é abolida, mas também não é utilizada de forma objetiva; a montagem neorrealista tenta, tão somente, organizar os planos-sequência em vista de contar uma história - sem fragmentação do espaço - , todo o resto é feito por quem assiste.

Munsterberg enxergava o realismo cinematográfico como presente somente no cinema objetivo, da fragmentação da montagem. O passar dos anos mostrou que o realismo estaria, também, naquele outro cinema que fora renegado pelo psicólogo: por meio da atenção voluntária é possível inserir o espectador no filme, fazê-lo dar sentido àquilo que o cineasta propositadamente deixou desconexo. Ou mesmo encontrar uma significação para uma imagem que esteja necessariamente desconexa e que peça esta participação do espectador na criação de um sentido para a continuação do filme.

O espectador se fazendo presente na obra dá significado àquelas imagens, busca um sentido para a narrativa. Os detalhes são postos em cena e não cabe mais ao diretor selecionálos e mostrar sua importância ao espectador, cabe a este ultimo selecioná-los em meio à multiplicidade de elementos presentes na imagem e dar a sua importância atestada pela narrativa que transcorre (ver a importância daquela arma que sutilmente o personagem no canto do quadro pega). 
O cinema feito a partir da década de 1930 que se vale dos longos planos-sequência se encaixa bem nesta teoria de Munsterberg. A seleção daquilo que é mostrado e a consequente fragmentação do espaço é reduzida ao mínimo (quando não excluída) para que melhor se utilize o espaço dramático. A câmera filma diversos eventos ocorrendo ao mesmo tempo e cabe ao espectador saber selecionar aquilo que teria maior importância para a compreensão da obra que lhe é apresentada. A teoria do psicólogo conecta-se neste ponto com a modernidade cinematográfica e com a teoria de seu grande defensor, André Bazin.

Quando Bazin escreve que a não fragmentação do espaço cênico levaria ao realismo cinematográfico, este realismo não se aproxima do cinema enquanto manifestação política, mas de um modelo que se aproxime mais do espectador. A ideia de o filme encontrar a expressão da duração do mundo faz o espectador aproximar-se da obra porque a sentiria próximo de seu modo próprio de experimentação do mundo. O corte é um modelo que pouco se aproxima da realidade. As pessoas não têm a possibilidade de promover o corte, elas vivem suas vidas como se fosse um único plano. A mise-en-scène do cinema moderno é realista porque abole os truques que a montagem poderia produzir.

O crítico francês escolhe como exemplo o curta-metragem O balão vermelho (LAMORISSE, 1956). Nele um garoto faz amizade com um balão de aniversário que o segue por todos os lados. Mais que isso: tem sentimentos, se irrita com o garoto, e fica triste. Esta relação poderia ser muito bem arranjada por truques feitos na mesa de montagem, pelo modo como seriam enquadrados o balão e o garoto. Mas seu autor prefere uma saída diferente: enquadra garoto e balão juntos num mesmo quadro eliminando as ideias de que as ações do balão seriam sugeridas 
pela montagem. A câmera é posta a distância e mostra o balão seguindo o garoto. Este não precisa tocar em seu brinquedo para fazê-lo se movimentar, é como se a matéria inerte tivesse ganhado vida e passasse a se mover por conta própria. Enquanto a montagem faria a sugestão de que o balão teria ganhado vida, o plano-sequência mostra que o balão ganhou vida.

Ainda no sentido de aproximar a teoria de Munsterberg da de Bazin é possível afirmar que, se o cinema moderno é bem sucedido em exprimir a duração do mundo, ele deveria ainda fazer com que o espectador passasse a fazer parte do espetáculo por meio da "atenção voluntária". Os planos-sequência não fariam a seleção daquilo que deveria ser visto pelo espectador, partiria deste a ação de selecionar o conteúdo do quadro em sua própria mente. Fazer aquilo que ele já faz em sua vida cotidiana. O filme deixaria de ser simplesmente assistido para ser experimentado.

A presença da câmera na mise-en-scène do cinema moderno - como já posto anteriormente - é de grande importância para a inserção do espectador no filme. É por meio de seu posicionamento (seja fixa, seja em movimento) no cenário que permite ao espectador participar do espetáculo cinematográfico. A câmera se torna seus olhos e, de certa maneira, seu corpo naquele ambiente. $\mathrm{O}$ espectador se faz virtualmente presente no mundo fantástico representado no filme - torna-se o voyeur de uma realidade fictícia. O espectador é um voyeur necessário que significa as imagens e sente o que lhe é sugerido sentir (o cinema moderno sugere, enquanto o cinema clássico impõe as emoções a serem sentidas - como ao fazer um close-up de uma criança chorosa, por exemplo). O grande objetivo deste cinema é o de tirar o espectador do estado de conforto em que fora posto - e ao qual se habituou - pelo cinema clássico. Poder-se-ia pensar 
ainda uma forma mais radical de cinema em que o filme seria constituído inteiramente de planos-sequência como se estivesse a colocar o espectador dentro dos cenários em que acontece o filme.

Esta proposta está presente no cinema do cineasta húngaro Béla Tarr. Em seus filmes, Tarr se vale de longos planos-sequência que mostram seus cenários por inteiro. Em raras ocasiões os cenários não são mostrados em sua completude. Sua câmera percorre as ruas seguindo seus personagens sem que seja feito o corte - o espectador faz o mesmo percurso que o personagem que vai de uma casa a outra no vilarejo de As harmonias de Werckmeister (TARR, 2000) ou saindo de dentro da casa e indo até o poço pegar água em $O$ cavalo de Turim (TARR, 2011), percurso que o próprio espectador faria se estivesse naquele cenário fisicamente.

Quando o protagonista de As harmonias de Werckmeister deixa o bar e caminha pela rua à noite, sua caminhada não é estranha ao espectador porque possui proximidade com sua própria vida. Suas caminhadas não são cortadas - quando uma pessoa caminha não ocorre um salto que a põe em seu objetivo final. Quando Tarr põe em seu filme estas ações feitas em sua completude ele permite ao espectador experimentar o seu filme, vivê-lo. A duração se assemelha àquela queé vivida pelo espectador em seu próprio cotidiano. A realidade (por mais fantástica que seja) é filmada em seu fluxo contínuo de acontecimentos, e assim é sentida. Quando em outro momento do filme a população se revolta e inicia uma onda de vandalismo, a câmera passa a ser os olhos de quem assiste. Este passeia pelos prédios simplesmente assistindo àquele caos sem que possa sofrer qualquer dano por não estar lá fisicamente - ele está presente "virtualmente".

É o que se dá em outra obra, desta vez do russo Alexandr Sokurov: Arca russa (2002). Mas desta vez a câmera será os 
olhos de um personagem. O filme é constituído de apenas um plano que permanece por toda a hora e meia de projeção. $\mathrm{O}$ espectador é este personagem que em momento algum aparece na frente da câmera, apesar de, em alguns momentos, ser possível ouvir sua voz. A experimentação do cinema chega a um nível extraordinário neste filme: o espectador se torna um dos personagens. E assim como não é concedida a possibilidade de uma pessoa ver o próprio rosto (a não ser na frente de um espelho) este protagonista russo também não terá seu rosto revelado. $\mathrm{O}$ espectador somente não possui voz, que é dada ao personagem. Mas nos é dada a possibilidade de enxergar com seus [do protagonista] olhos, aquela condição privilegiada do sujeito que se relaciona com a realidade.

Em ambos os casos é concebida uma realidade fantástica. Mas ainda assim é dada a possiblidade do espectador de acreditar no realismo do filme devido à forma que lhe é empregada. $\mathrm{O}$ espectador passa a ser ativo no visionamento do filme, ainda que não possa mudar os caminhos da trama. É a consciência do cinema de necessitar de um espectador para existir.

\section{NOTAS}

${ }^{1}$ Graduando em Filosofia pela Universidade Estadual de Feira de Santana (UEFS).yvessaopaulo@gmail.com

${ }^{2}$ Bazin, apesar de utilizar o termo central da filosofia de Bergson, diz que sua noção de duração se distingue do caráter "psicologista" dado pelo filósofo. O termo duração não raro é utilizado por teóricos de cinema, a exemplo de Marcel Martin em A linguagem cinematográfica. 


\section{REFERÊNCIAS:}

MUNSTERBERG, Hugo; $A$ atenção. In: Ismail Xavier (org.). A experiência do cinema. Tradução: Teresa Machado; Rio de Janeiro: Edições Graal: Embrafilmes, 1983. P. 27 - 35.

BAZIN, André; O que é o cinema?. Tradução: Eloisa Araújo Ribeiro; $1^{a}$ ed. São Paulo: Cosac Naify, 2014.

CHAPLIN, Charles. Minha Vida. Tradução: Rachel de Queiroz, R. Magalhães Júnior, Genolino Amado; $16^{\mathrm{a}}$ ed. Rio de Janeiro: José Olympio, 2012.

XAVIER, Ismail: $O$ discurso cinematográfico: a opacidade e a transparência. Rio de Janeiro: Paz e Terra, 1977.

OLIVEIRA JR., L. C. G; O cinema de fluxo e a mise-en-scène. 2010. Dissertação - USP. PDF.

NORMAND, Mabel: Carlitos no hotel. EUA, 1914: duração; 17 $\min$.

COUSINS, Mark; The story of film: an odyssey. Reino Unido, 2011; duração: 1 h.

RENOIR, Jean; A regra do jogo. França, 1936; duração: 1h 50 $\min$.

HITCHCOCK, Alfred; Festim diabólico. EUA, 1948; duração: 1h $20 \mathrm{~min}$.

WELLES, Orson; Cidadão Kane. EUA, 1941; duração: 1h 59 $\min$. 
SCORSESE, Martin; Os bons companheiros. EUA, 1990; duração: 2h 26 min.

ROSSELLINI, Roberto; Roma, cidade aberta. Itália, 1945; duração: 1h $49 \mathrm{~min}$.

LAMORISSE, Albert; O balão vermelho. França, 1956; duração: $34 \mathrm{~min}$.

TARR, Béla; As harmonias de Werckmeister. Hungria, 2000; duração: 2h 25 min.

TARR, Béla; O cavalo de Turim. Hungria, França, Alemanha, Suiça, 2011; duração: 2h 26 min.

SOKUROV, Aleksandr; Arca russa. Russia, Alemanha, Canadá, Finlândia, Dinamarca, 2002; duração: 1h 39 min. 